\title{
P- AND N-TYPE DOPING OF MBE GROWN CUBIC GaN/GaAs EPILAYERS
}

\author{
D.J. As, ${ }^{*}$ T. Simonsmeier, * J. Busch,* B. Schöttker,* M. Lübbers, * J. Mimkes,* \\ D. Schikora,* K. Lischka,* W. Kriegseis, ${ }^{* *}$ W. Burkhardt,** B.K. Meyer** \\ * Universität Paderborn, FB-6 Physik, Warburger Straße 100, \\ D-33095 Paderborn, Germany, d.as@uni-paderborn.de \\ ** Universität Giessen, I. Physik. Inst. , Heinrich-Buff-Ring 16, \\ D-35392 Giessen, Germany
}

Cite this article as: MRS Internet J. Nitride Semicond. Res. 4S1, G 3.24 (1999)

\begin{abstract}
P-type doping with $\mathrm{Mg}$ and n-type doping with Si of cubic $\mathrm{GaN}$ (c-GaN) epilayers is reported. Cubic GaN films are grown by rf-plasma assisted MBE on semi-insulating GaAs (001) substrates at a substrate temperature of $720^{\circ} \mathrm{C}$. Elemental $\mathrm{Mg}$ and $\mathrm{Si}$ are evaporated from thermal effusions cells. Secondary ion mass spectroscopy (SIMS), low temperature photoluminescence (PL) and temperature dependent Hall-effect measurements are used to study the incorporation, optical and electrical properties. $\mathrm{A} \mathrm{Mg}$ related shallow donor-acceptor transiton at $3.04 \mathrm{eV}$ with an acceptor activation energy of $\mathrm{E}_{\mathrm{A}}=0.230 \mathrm{eV}$ is observed by low temperature PL. At $\mathrm{Mg}$ concentrations above $10^{18} \mathrm{~cm}^{-3}$ the dominance of a broad blue band indicates that also in $\mathrm{c}-\mathrm{GaN} \mathrm{Mg}$ is incorporated at different lattice sites or forms complexes. Si-doped c-GaN epilayers are ntype with electron concentrations up to $5^{*} 10^{19} \mathrm{~cm}^{-3}$. The incorporation of $\mathrm{Si}$ follows exactly the vapor pressure curve of $\mathrm{Si}$, indicating a sticking coefficient of 1 for $\mathrm{Si}$ in c$\mathrm{GaN}$. With increasing Si-concentration the intensity of the near-band luminescence continuously increases and broadens.
\end{abstract}

\section{INTRODUCTION}

Cubic GaN (c-GaN) epilayers grown by molecular beam epitaxy (MBE) show outstanding electrical and optical features [1,2], demonstrating the high potential of c$\mathrm{GaN}$ for the realization of blue emitting laser diodes. Gain measurements in undoped cubic material reveal gain values which are comparable to that of the best hexagonal $\mathrm{GaN}$ (h-GaN) [3]. Particularly, epitaxially grown layers of c-GaN lend themselves to the production of cleaved laser cavities and optically excited stimulated emission from such cleaved facetts has already been observed [4]. In order to fabricate almost any device it is necessary to carry out controlled doping of $\mathrm{GaN}$ in order to realize both $\mathrm{n}$-type and $\mathrm{p}$ type $\mathrm{GaN}$ material. In hexagonal $\mathrm{GaN}$ the principal p-type dopant is $\mathrm{Mg}$ and $\mathrm{n}$-type dopant is $\mathrm{Si}$.

In this paper we summarize recent doping experiments of cubic $\mathrm{GaN}$ epilayers by $\mathrm{Mg}$ and $\mathrm{Si}$. Secondary ion mass spectroscopy (SIMS), low temperature photoluminescence (PL) and temperature dependent Hall-effect measurements are used to study the incorporation, the optical and electrical properties of $\mathrm{Mg}$ - and $\mathrm{Si}$-doped samples. 


\section{EXPERIMENTAL}

Cubic GaN films are grown by rf-plasma assisted MBE on semi-insulating GaAs (001) substrates at a substrate temperature of $720^{\circ} \mathrm{C}$. The growth rate is about $0.07 \mu \mathrm{m} / \mathrm{h}$ and the thickness of the layers is about $1 \mu \mathrm{m}$, respectively. Elemental $\mathrm{Mg}$ and $\mathrm{Si}$ are evaporated from commercial effusion cells at source temperatures between $260^{\circ} \mathrm{C}$ and $450^{\circ} \mathrm{C}$, and $750^{\circ} \mathrm{C}$ and $1150^{\circ} \mathrm{C}$, respectively. The concentration and depth distribution of $\mathrm{Mg}$ is measured by secondary ion mass spectroscopy (SIMS) using $\mathrm{Mg}$ implanted calibrated standards for quantification, and an $\mathrm{O}^{2+}$ primary beam of $6 \mathrm{keV}$. Photoluminescence (PL) measurements are performed in a He bath cryostat at $2 \mathrm{~K}$. Luminescence is excited by the $325 \mathrm{~nm}$ line of a cw HeCd UV laser with a power of $3 \mathrm{~mW}$ and measured in a standard PL-system. Hall-effect measurements are performed using square shaped samples (Van der Pauw geometry) in a cryostat between $240 \mathrm{~K}$ to $380 \mathrm{~K}$, at a magnetic field of $0.3 \mathrm{~T}$ and with the sample in the dark.

\section{RESULTS AND DISCUSSION}

\section{Mg doping of cubic GaN}

The $2 \mathrm{~K}$ photoluminescence spectra of cubic $\mathrm{GaN}$ epilayers grown at different $\mathrm{Mg}$ source temperatures $\mathrm{T}_{\mathrm{Mg}}$ is shown in Fig.1. The lowest spectrum is that of an undoped reference sample grown before introducing $\mathrm{Mg}$ into the chamber. The near band edge luminescence of the reference sample is dominated by an excitonic transition $\mathrm{X}$ at 3.26 $\mathrm{eV}$ and an omnipresent donor-acceptor pair transition $\left(\mathrm{D}^{0}, \mathrm{~A}^{0}\right)$ at $3.15 \mathrm{eV}$ [5]. The nature of the involved shallow donor and acceptor is not identified up to now. The corresponding binding energies are $25 \mathrm{meV}$ and $130 \mathrm{meV}$, respectively. $\mathrm{Mg}$-doping at source temperatures $\mathrm{T}_{\mathrm{Mg}}$ below $300^{\circ} \mathrm{C}$ results in the appearence of a donor acceptor transition $\left(\mathrm{D}^{0}, \mathrm{~A}^{0}{ }_{\mathrm{Mg}}\right)$ at $3.04 \mathrm{eV}$. At about $60 \mathrm{~K}$ this transition thermalizes to the corresponding band acceptor transition $\left(\mathrm{e}, \mathrm{A}_{\mathrm{Mg}}^{0}\right)$ at about $3.07 \mathrm{eV}$. The donor participating in this line has the same ionization energy as the one observed in the undoped sample. From the energetic position an acceptor activation energy of $\mathrm{E}_{\mathrm{Mg}}$ $=0.230 \mathrm{eV}$ is estimated. This energy level is in excellent agreement with recent theoretical calculations of $\mathrm{Mg}_{\mathrm{Ga}}$ for $\mathrm{c}-\mathrm{GaN}$ [6] and is somewhat lower than that for the corresponding value of $0.265 \mathrm{eV}$ for $\mathrm{h}-\mathrm{GaN}$ [7]. Detailed characteristics of the temperature and intensity dependence of the PL spectra will be presented elsewhere. At $\mathrm{Mg}$ concentrations higher than $10^{18} \mathrm{~cm}^{-3}\left(\mathrm{~T}_{\mathrm{Mg}}\right.$ higher than $\left.350^{\circ} \mathrm{C}\right)$ the low energy side of the spectrum will be dominated by a broad blue emission band centered at about $2.8 \mathrm{eV}$, which is modulated due to interference fringes of the PL light (upper curves in Fig.1). The nature of this deep transition is unknown up to now, however it seems that also in c$\mathrm{GaN} \mathrm{Mg}$ is incorporated at different lattice sites or forms complexes at high $\mathrm{Mg}$ flux. A recent publication on $\mathrm{h}-\mathrm{GaN}$ attributes this blue band to $\mathrm{Mg}-\mathrm{V}_{\mathrm{N}}$ complexes [8]. Rapid thermal annealing experiments in $\mathrm{N}_{2}$ atmosphere (30 s) show that the responsible defect for the blue band is thermally stable up to an annealing temperature of $1100^{\circ} \mathrm{C}$.

The full squares in Fig.2 show the amount of incorporated Mg measured by SIMS versus the beam equivalent pressure of $\mathrm{Mg}\left(\mathrm{BEP}_{\mathrm{Mg}}\right)$. The $\mathrm{Mg}$ concentration remains below about $5^{*} 10^{18} \mathrm{~cm}^{-3}$ and is nearly independent on the arrival rate of supplied $\mathrm{Mg}$, which varied by four orders of magnitude. This behaviour is similar to that observed 


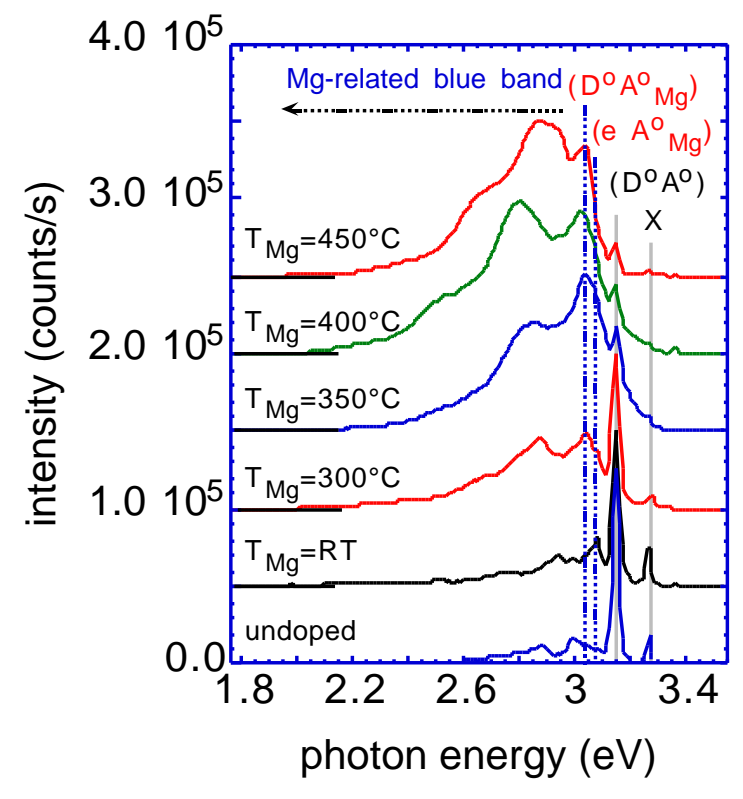

Fig. 1: Low temperature $2 \mathrm{~K}$ photoluminescence spectra of $\mathrm{Mg}$ doped cubic GaN epilayers grown by different $\mathrm{Mg}$ source temperature $T_{M g}$. $\left(X\right.$ excitonic transition, $\left(D^{\circ}, A^{\circ}\right)$ omnipresent donor-acceptor pair transition). The dashed lines indicate the shallow Mg-related transitions $\left(D^{\circ}, A^{\circ}{ }_{M g}\right)$ and $\left(e, A^{\circ}{ }_{M g}\right)$. The dashed arrow below $2.95 \mathrm{eV}$ indicates the deep $\mathrm{Mg}$-related blue band, which is modulated due to interference fringes of the PL light.

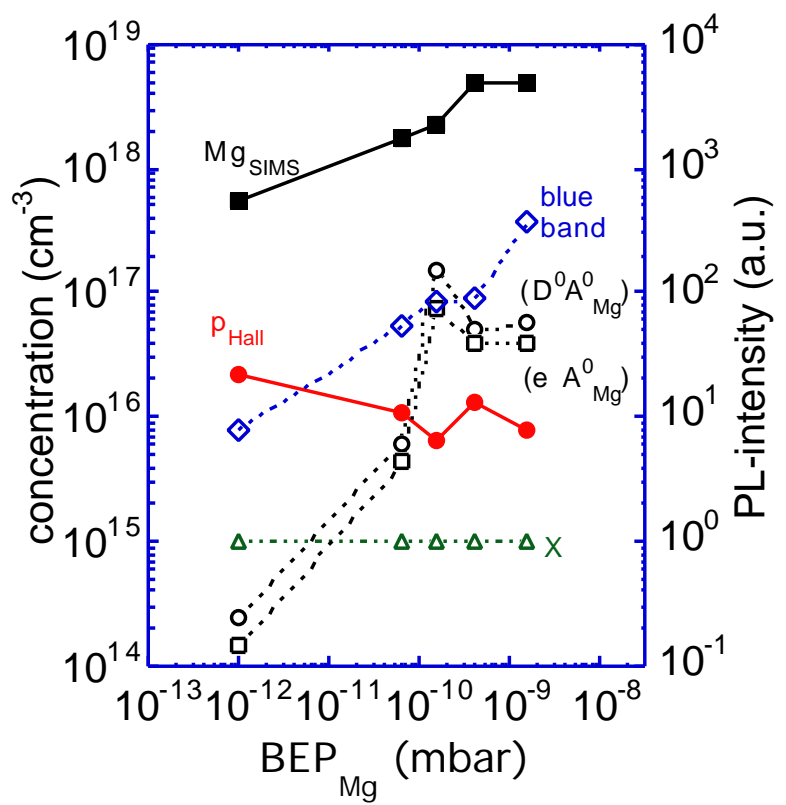

Fig. 2: Integral PL intensity of various observed transitions (open symbols), $\quad \mathrm{Mg}$ concentration measured by SIMS (full squares), and free hole concentration $p_{\text {Hall }}$ at room temperature versus beam equivalent pressure $\left(B E P_{M_{g}}\right)$ of the offert Mg flux.

for MBE growth of hexagonal $\mathrm{GaN}$ [9] and GaAs [10] and is expected to be due to the high vapor pressure of $\mathrm{Mg}$. Depth profile measurements show a homogenious distribution of $\mathrm{Mg}$ within the top epilayer and an accumulation of $\mathrm{Mg}$ by one order of magnitude at the GaN/GaAs interface [11]. This may be due to the increased number of structural defects near the interface incorporated as a result of the large lattice mismatch between substrate and epilayer.

Hall-effect measurements of the Mg-doped cubic GaN epilayers show p-type conductivity without postgrowth treatments. For the sample grown at a $\mathrm{Mg}$ source temperature of $\mathrm{T}_{\mathrm{Mg}}=300^{\circ} \mathrm{C}$ the measured free hole concentration $\mathrm{p}_{\mathrm{Hall}}$ and hole mobility at room temperature is about $3 * 10^{16} \mathrm{~cm}^{-3}$ and $215 \mathrm{~cm}^{2} / \mathrm{Vs}$, respectively. This low hole concentration is expected due to the high ionization energy of $\mathrm{Mg}\left([\mathrm{Mg}]_{\mathrm{SIMS}}=\right.$ $\left.1.7 * 10^{18} \mathrm{~cm}^{-3}\right)$. Under the assumption of compensation the temperature dependence of the concentration of free holes yields for the shallow $\mathrm{Mg}$ acceptor an activiation energy of $\mathrm{E}_{\mathrm{Mg}}=0.110 \pm 0.020 \mathrm{eV}$ [12]. The corresponding value for hexagonal $\mathrm{GaN}$ is $160 \pm 5$ meV [13]. In both cases the thermal activation energies are much lower than the optical activation energies. The reason for this may be either due to a strong electron lattice coupling [14] since the Bohr radius of the "shallow" effective mass like acceptor state is 
only $6.3 \AA$ or due to potential fluctuations [15]. The room temperature free hole concentration $\mathrm{p}_{\mathrm{Hall}}$ versus the beam equivalent pressure of $\mathrm{Mg}\left(\mathrm{BEP}_{\mathrm{Mg}}\right)$ is depicted in Fig. 2 by full circles. In contradiction to the Mg concentration measured by SIMS no increase of $\mathrm{p}_{\mathrm{Hall}}$ vs. $\mathrm{BEP}_{\mathrm{Mg}}$ is seen, indicating that an additional compensating donor may be incorporated during Mg-doping.

This assumption is constrained by our PL-measurements. Using Gaussian functions for the different transitions to fit the measured spectra, the integral intensities of the different PL-lines are estimated and also depicted in Fig. 2 versus $\mathrm{BEP}_{\mathrm{Mg}}$ (open symbols). Both the shallow transitions, $\left(\mathrm{D}^{0}, \mathrm{~A}_{\mathrm{Mg}}^{0}\right)$ and $\left(\mathrm{e}, \mathrm{A}_{\mathrm{Mg}}^{0}\right)$, as well as the deep blue band show a clear increase with increasing $\mathrm{Mg}$-flux. Therefore all three transitions are related to the incorporation of $\mathrm{Mg}$ into $\mathrm{c}-\mathrm{GaN}$. However, whereas the shallow transitions seems to saturate at higher Mg-flux, this is not the case for the blue band. Since the measured hole concentration is nearly independent of the supplied $\mathrm{Mg}$ amount we conclude that the blue band may act as a compensating deep donor center. This conclusion is in agreement with similar observations made in h-GaN [16]. For p-type $\mathrm{GaN}$ theoretical calculations also show that $\mathrm{Mg}_{\mathrm{i}}, \mathrm{Mg}_{\mathrm{N}}$ or $\mathrm{Mg}-\mathrm{V}_{\mathrm{N}}$ may act as compensating deep donors. Since the formation energies of all these Mg-related defects are low enough they may be possible candidats for the blue band in GaN.

\section{$\underline{\text { Si-doping of cubic GaN }}$}

The optical properties of $\mathrm{Si}$ doped cubic $\mathrm{GaN}$ are shown in Fig. 3. At $2 \mathrm{~K}$ the spectrum of the sample grown with the lowest $\mathrm{Si}$-flux (source temperature $\mathrm{T}_{\mathrm{Si}}=750^{\circ} \mathrm{C}$ ) is dominated by the excitonic transition $\mathrm{X}$ at $3.26 \mathrm{eV}$ and the omnipresent donor-acceptor pair transition $\left(\mathrm{D}^{\circ}, \mathrm{A}^{\circ}\right)$ at $3.15 \mathrm{eV}$ [5]. With increasing $\mathrm{Si}$ flux a clear shift to higher energies of the $\left(\mathrm{D}^{\circ}, \mathrm{A}^{\circ}\right)$ and an increase of the full width at half maximum (FWHM) is observed. For samples grown at $\mathrm{T}_{\mathrm{Si}}>1025^{\circ} \mathrm{C}$ both lines merge to one broad band. This behavior is similar to the one observed in the well known case of GaAs heavily doped with Si or Te and can well be described by electron-impurity interactions (band tailing), shrinkage of the band gap due to exchange interaction among free carriers and conduction band filling effects $[17,18]$. A detailed analysis of the PL-spectra will be published elsewhere.

For $\mathrm{Si}$ doped cubic $\mathrm{GaN}$ epilayers the free electron concentration at room temperature (measured by Hall-effect) is depicted in Fig. 4 as a function of the Si-effusion cell temperature (full triangles). One clearly sees that the free electron concentration nearly exactly follows the Si-vapor pressure curve (full line in Fig.4) [19]. This indicates a constant sticking coefficient of Si at the growth temperature chosen. Nearly all Si atoms are incorporated at Ga sites and act as shallow donors. Temperature dependent Halleffect measurements further show that $\mathrm{c}-\mathrm{GaN}$ grown at $720^{\circ} \mathrm{C}$ and a $\mathrm{Si}$ source temperature $\mathrm{T}_{\mathrm{Si}} \geq 1025^{\circ} \mathrm{C}$ are totally degenerated with a maximum free electron concentration of $5^{*} 10^{19} \mathrm{~cm}^{-3}$ and an electron mobility of $75 \mathrm{~cm}^{2} / \mathrm{Vs}$, respectively. This clearly demonstrates the ability of controlled n-type doping of cubic GaN by Si up to concentrations which are necessary for the fabrications of laser diodes. 


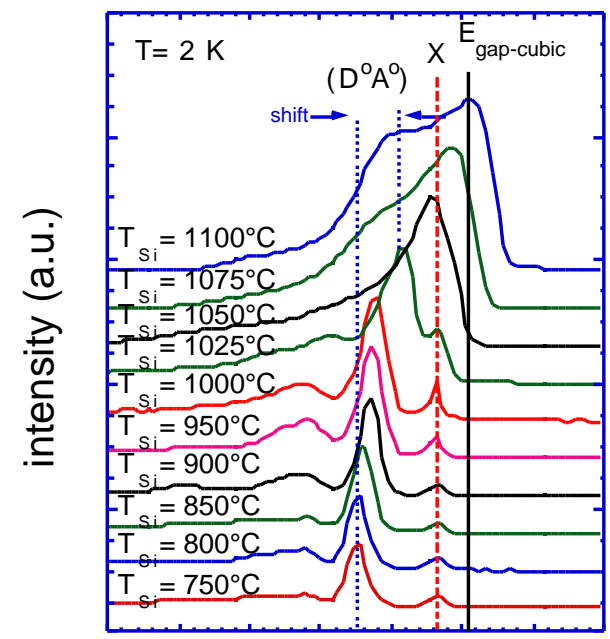

2.82 .933 .13 .23 .33 .43 .5

photon energy $(\mathrm{eV})$

Fig. 3: Low temperature PL spectra of Si doped cubic GaN epilayers grown with different $\mathrm{Si}$ source temperatures $T_{S i}$. With increasing $S i$ source temperature the $\left(D^{\circ}, A^{\circ}\right)$ transition broadens and shifts to higher photon energies.

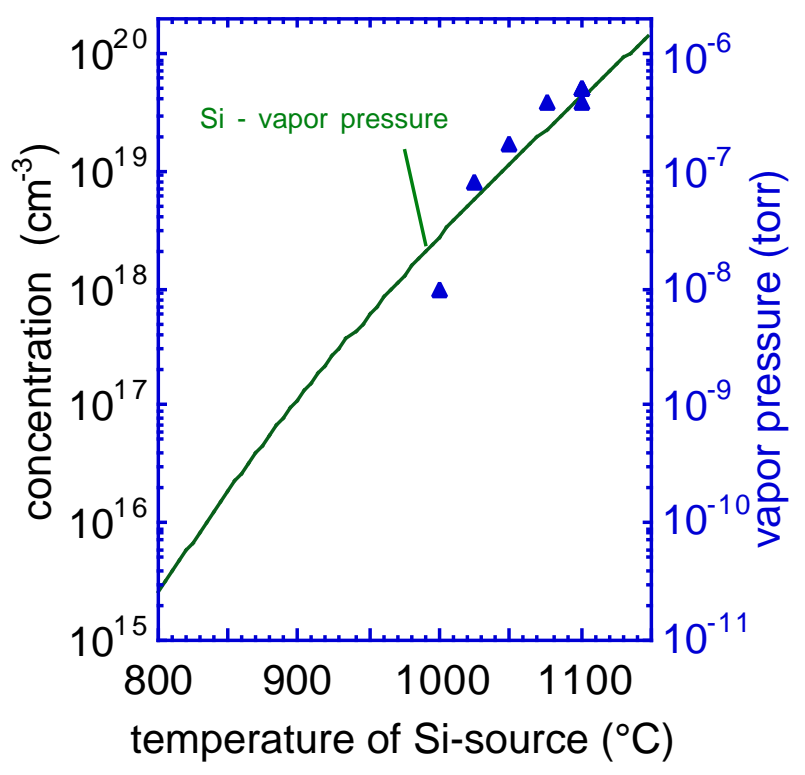

Fig. 4: Room temperature free electron concentration measured by Halleffect (full triangles) versus Si source temperature. The full line represents the vapor presure curve of Si after [19].

\section{CONCLUSIONS}

Cubic GaN films grown by rf-plasma assisted MBE on semi-insulating GaAs (001) substrates are doped by $\mathrm{Mg}$ and $\mathrm{Si}$, yielding $\mathrm{p}$ - and n-type conductivity, respectively. A $\mathrm{Mg}$ related shallow donor-acceptor transition at $3.04 \mathrm{eV}$ with an optical acceptor activation energy of $\mathrm{E}_{\mathrm{A}}=0.230 \mathrm{eV}$ is observed by low temperature PL. At $\mathrm{Mg}$ concentrations above $10^{18} \mathrm{~cm}^{-3}$ a broad blue band dominates the PL spectra and indicates that also in cubic $\mathrm{GaN} \mathrm{Mg}$ is incorporated at different lattice sites or forms complexes. Hall-effect measurements show that this complex may act as a compensating donor. Si-doping follows exactly its vapor pressure curve, indicating a constant sticking coefficient in the investigated temperature range. With increasing Si-concentration a continuous increase and broadening of the near-band luminescence is measured. Sidoped c-GaN epilayers are n-type with electron concentrations up to $5^{*} 10^{19} \mathrm{~cm}^{-3}$.

\section{ACKNOWLEDGEMENTS}

The authors acknowledge the support of their work by "Deutsche Forschungsgemeinschaft", project number As (107/1-1). 


\section{REFERENCES}

1. D.J. As, D. Schikora, A. Greiner, M. Lübbers, J. Mimkes, and K. Lischka, Phys. Rev. B 54 (16), R11118 (1996)

2. D. Schikora, M. Hankeln, D.J. As, K. Lischka, T. Litz, A. Waag, T. Buhrow and F. Henneberger: Phys. Rev. B 54 (12), R8381 (1996)

3. J. Holst, L. Eckey, A. Hoffmann, I. Broser, B. Schöttker, D.J. As, D. Schikora and K. Lischka: Appl. Phys. Lett. 72 (12), 1439 (1998)

4. J. Holst, A. Hoffmann, I. Broser, B. Schöttker, D.J. As, D. Schikora and K. Lischka: submitted to Appl. Phys. Lett.

5. D.J. As, F. Schmilgus, C. Wang, B. Schöttker, D. Schikora, and K. Lischka: Appl. Phys. Lett. 70 (10), 1311 (1997)

6. J. Neugebauer, C.G. Van de Walle, MRS Symp. Proc. Vol. 395, 645 (1996)

7. M. Leroux, B. Beaumont, N. Grandjean, J. Massies, P. Gibart: MRS Symp. Proc.Vol. 449, 695 (1997)

8. U. Kaufmann, M. Kunzer, M. Maier, H. Obloh, A. Ramakrishnan, B. Santic, P. Schlotter, Appl. Phys. Lett. 72 (11) 1326 (1998)

9. S. Guha, N.A. Bojarczuk, and F. Cardone, Appl.Phys.Lett. 71 (12), 1685 (1997)

10. C.E.C.Wood, D. Destimone, K.Singer, and G.W.Wicks, J.Appl.Phys. 53, 4230 (1982)

11. D.J. As, T. Simonsmeier, B. Schöttker, T. Frey, D. Schikora, W. Kriegseis, W. Burkhardt, and B.K. Meyer, Appl.Phys. Lett. 73 (13), 1835 (1998)

12. D.J. As, Phys. Stat. Sol. (b) 210, 2. Dec. (1998)

13. W. Kim, A. Salvador, A.E. Botchkarev, O. Aktas, S.N. Mohammad, and H. Morcoc, Appl. Phys. Lett. 69 (4), 559 (1996)

14. B.K. Ridley, in "Quantum Processses in Semiconductors", $2^{\text {nd }}$ Ed., Clarendon Press, Oxford, 1988, p.235

15. D.J. Dewsnip, J.W. Orton, D.E. Lacklison, L. Flannery, A.V. Andrianov, I. Harrison, S.E. Hooper, T.S. Cheng, C.T. Foxon, S.N. Novikov, B. Ya Ber, and Yu A.

Kudriavtsev, Semicond. Sci. Technol. 13, 927 (1998)

16. L.Eckey, U.von Gfug, J.Holst, A.Hoffmann, B.Schineller, K.Heime, M.Heuken, O.Schön, R.Beccard, J. of Crystal Growth 189/190, 523 (1998)

17. A.P. Abramov, I.N. Abramova, S. Yu. Verbin, I. Ya. Gerlovin, S.R. Grigorév, I.V. Ignatév, O.Z. Karimov, A.B. Novikov, and B.N. Novikov, Semiconductors 27 (7), 647 (1993)

18. J. De-Sheng, Y. Makita, K. Ploog, H.J. Queisser, J. Appl. Phys. 53 (2), 999 (1982)

19. J.L. Souchiere, Vu Thien Binh, Surface Science 168, 52 (1986) 